\title{
Optimization of development schemes for group water supply systems under uncertainty of prospective water consumption
}

\author{
Roman V. Chupin ${ }^{1}$, Minh Ngoc Pham ${ }^{2 *}$, Viktor R. Chupin ${ }^{1}$ \\ ${ }^{1}$ Irkutsk National Research Technical University, 83, Lermontov St., Irkutsk 664074, Russia \\ ${ }^{2}$ Vinh University, 182 Le Duan St., Vinh, Vietnam
}

\begin{abstract}
In recent years, in the Russian cities there has been a decrease about $15-30 \%$ the total volume of water consumed and the specific indicator of water consumption per resident. However, this phenomenon is not taken into account in the SP 31.13330.2012, therefore the values of specific water consumption do not correspond to the modern level of sanitary equipment of the buildings and water consumption, which can not be the same for all cities and towns in Russia. Using the standard values of the design loads indicated in this code can lead to a significant increase in the cost of the project and operating costs. Their correction is necessary taking into account the assessment and forecast of the actual values of specific water consumption. This requires appropriate research and updating of specific water consumption standards for the design and reconstruction water supply and sewerage systems. The article describes the parameter justification method for the designed water supply systems under uncertainty of the prospective values of specific water consumption. The technique is based on the fuzzy sets theory and decision-making methodology under uncertainty of the initial information. This technique allows you to make decisions based on the minimum values of investment risks.
\end{abstract}

\section{Introduction}

The operating experience water supply systems in populated areas of Russia performed under the 80 s of the last century, made it possible to determine the actual water consumption per resident with varying degrees of improvement in residential areas and in different climatic zones [1]. Analysis and processing of these materials provided an opportunity to develop averaged specific water consumption standards, which were the basis of SNiP 2.04.02-84 "Water supply. External systems and facilities", and on the basis of which the designers calculated the required amount of water when designing new water supply systems and waterworks. However, in recent years in Russia there has been a decrease in the total water consumption in cities $15-30 \%$ and, accordingly, a decrease in the specific water consumption for household needs of the population [2].

\footnotetext{
*Corresponding author: minhrow@gmail.com
} 
Reducing water consumption has led to a reduction in water consumption in pipelines, and at the same time, problems have arisen in the operation of facilities and pipelines, namely:

- Water flow rates in pipelines decreased and terms of water exchange increased;

- Decreased frequency of water exchange, which led to deterioration of water quality in pipelines.

In the conditions of Siberia, individual water pipelines, in which water speeds have become less than standard values, are at risk of freezing. In the sewage systems, the amount of sediments increased and, as a result, the number of failures and the time for their elimination (cleaning) increased, the sewage treatment plants and pumping stations began to work in inefficient and energy-intensive operation modes.

We believe that when updating SNiP 2.04.02-84 "Water supply. External systems and facilities" and the introduction of SP 31.13330.2012, regarding the assignment of specific water consumption values, the factors cited above are not taken into account and therefore this document requires revision.

The current level of urbanization in the Russian Federation, and indeed in all countries of the world, is characterized by the fact that the number of people living in cities and populated territories varies with different migration processes. [3]. The developers of general plans and programs for the integrated development of the engineering infrastructure of some cities are faced with the fact that the population and specific indicators of the consumption of public services are decreasing. At the same time, systems and facilities become underloaded, although they have significant wear (60-80\%). However, it is not known what water consumption will be in 15-30 years. The problem of forecasting and forming calculated specific water consumption values and, consequently, determining the parameters of water supply systems during the development of cities and settlements is related to optimization problems in the conditions of uncertainty of the initial information.

\section{Method}

In this respect, models and methods based on the use of models of fuzzy sets [4] and interval mathematics [5] are new and effective. Their essence lies in the fact that the characteristic function (the function of belonging of an element to a set) can take any values in the interval $(0 ; 1)$, and not just the values 0 or 1 .

Using models of fuzzy sets, the representation of the specific water consumption rate for household needs of the population $220 \div 2801 /$ person per day recommended by SP 31.13330 .2012 can be expressed by a fuzzy set using the membership function $\mu_{\mathrm{a}}(\mathrm{x})$ : $\mathrm{X} \rightarrow[0.1]$ a linear triangular and trapezoidal shape (see. Fig. 1).
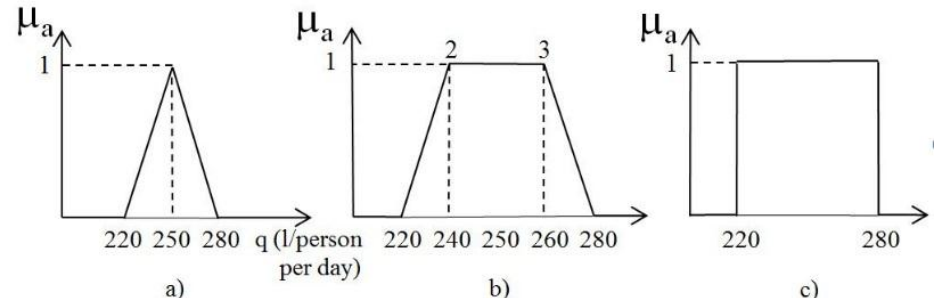

c)

Fig. 1. Fuzzy representation of perspective water consumption: a - triangular; b - trapezoidal; c - interval (rectangular) form

For triangular, trapezoidal and rectangular shapes, fuzzy sets can be written as follows:

$$
q^{a}=\{220|0 ; 250| 1 ; 280 \mid 0\}
$$




$$
\begin{gathered}
q^{b}=\{220|0 ; 240| 1 ; 260|1 ; 280| 0\} ; \\
q^{c}=\{219,9|0 ; 220| 1 ; 280|1 ; 280,19| 0\},
\end{gathered}
$$

$q^{a}, q^{b}, q^{c}$ - possible values of specific water consumption and their membership function in the representation of fuzzy triangular, trapezoidal and rectangular shapes. According to the presented notes, water consumption up to a value of $2201 /$ person per day inclusive has a membership degree of 0 , as well as water consumption greater than 280 1/person per day. For water consumption from 220 to 250 , the membership degree increases from 0 to 1 , and for water consumption in the range from 250 to 280 decreases from 1 to 0 . Obviously, each form of representation of a fuzzy set will have its own time interval. For example, experts determined the specific water consumption interval for the future in the amount of 220-280 $1 /$ person per day, based on the fact that in the current year the actual specific water consumption mattered was close to $2501 /$ person per day. There is no certainty that in subsequent periods it will increase or decrease. Consequently, the membership function can be viewed in the form of a triangular shape (Fig. 1a). If there is confidence that the prospective specific water consumption will be in the range of 240-260 1/person per day from a possible 220-280 1/person per day, the membership function can be viewed as a trapezium (Fig. 1b). If there is confidence that the prospective specific water consumption will be in the range of 220-280 1/person per day from the possible 220-280 1/person per day, the membership function can be viewed as a rectangle (Fig. 1c). Obviously, each representation form of a fuzzy set of specific water consumption will correspond to a certain temporary stage in the development of a water supply and wastewater system. For example, if a prospective scheme is considered for a period of 15 years in three construction stages, then to justify the parameters of the first stage, the preferred form of a fuzzy set will be triangular, the second is trapezoidal, and the third is rectangular.

Assuming that due to energy and resource saving measures the specific water consumption will decrease and reach a rational (minimum) value, for example $150 \mathrm{l} / \mathrm{person}$ per day, fuzzy sets for three time intervals can be represented as the following sequence of triangular forms (Fig. 2).

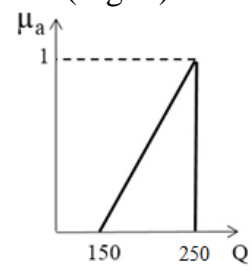

a)

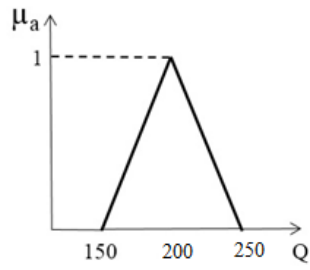

b)

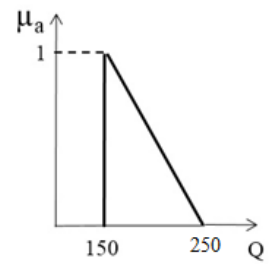

c)

Fig. 2. Fuzzy representation of specific water consumption in terms of its reduction

When economic evaluation and comparison of options for the development of systems and facilities, the values of the membership function can be considered as follows. Formed many specific values of water consumption. For example, the interval of specific values of $220-2801 /$ person per day is divided in equal parts of $220,230, \ldots, 2801 /$ person per day and for each fixed value of specific water consumption a membership degree from 0 to 1 is assigned. Further, for each fixed value specific water consumption solves the problem of justifying the parameters of new and reconstructed system parts and determines the cost of this option. As a result, we obtain a set of values of the cost options with the corresponding membership function. The membership function in this case can be interpreted as trust or distrust of the cost values of the analyzed options. Distrust can be expressed in the form of the coefficient of appreciation, which can be defined as follows: 


$$
K_{u}=1+\left(1-\mu_{a}(x)\right) .
$$

Obviously, for the rectangular shape of the membership function (Fig. 1c), for all options for the development and reconstruction of water supply and wastewater systems, the coefficient of appreciation will be equal to 1 . The choice of the preferred option for realization requires an assessment of possible risks. The risk - we mean additional expenses in the reconstruction of the water supply and wastewater system if the designated specific water consumption will be less than the actual at the time of the project, and unnecessary expenses (deadening of capital investments), if the selected specific water consumption value is greater than it will be in reality. The option with the least risks will be preferable.

For the criterion of evaluating design options for water supply systems, we accept total reduced costs for one year for the construction and operation of all system elements, including the cost of electricity for pumping and transporting.

$$
Z=\left(E+f_{c}\right) \cdot K+c_{e} \cdot E_{g}
$$

where $Z$ - reduced costs; $K$ - capital investment; $E$ - coefficient of investment efficiency, which in the conditions of market economy is identified with bank interest; $f_{c}$ - share of depreciation charges, system repair and maintenance; $c_{e}$ - the unit cost of electricity; $E_{g}$ annual electricity demand. To concretize the reduced costs, the paper used the information given in the enlarged standards of construction prices [6].

The boundary values of the specific calculated water consumption can be assigned not only according to the requirements of SP 31.13330 .2012 , but also be determined on the basis of an analysis of the actual specific water consumption, prediction options (optimistic and pessimistic) of the population, the volume of housing construction and the degree of sanitarytechnical equipment of buildings for future development and other $[7,8]$.

\section{Examples and discussions}

Example 1. We make a parameter justification of a $1 \mathrm{~km}$ long water supply system from polyethylene pipes, through which water is supplied to a prospective development area per 100 thousand people. In the current year, the actual specific water consumption in the city was 250 1/person per day. For the calculated values of specific wastewater we take it in the range of $220-280 \mathrm{l} /$ person per day [9]. Therefore, for this example, the interval of the estimated water consumption of the pipeline will be as follows: $0.173-0.324 \mathrm{~m}^{3} / \mathrm{s}$. Given the values of actual water consumption, the membership function has a triangular shape (Fig. 2a). To build this function, the possible load interval is divided into the following values: $Q$ $=(0.173|0.01 ; 0.211| 0.5 ; 0.249|1.0 ; 0.287| 0.5 ; 0.324 \mid 0.01)$

For each load value we define the pipeline diameters, the values of the membership function and the reduced costs (taking $\mathrm{E}=0.12$; speed $3 \mathrm{~m} / \mathrm{s}$ ). The results of the calculations are presented in table 1.

The preferred option is with a design flow rate of $0.249 \mathrm{~m} 3 / \mathrm{s}$. However, before making a final decision, it is required to assess the risks. To do this, using the decision-making methodology $[10,11]$, and build a "risk matrix", which for the example under consideration is presented in table 2 . In this matrix, the values of the calculated load are presented in the first row and first column. Zero values of additional expenses are located on the diagonal, which means that the accepted value of expenses coincides with those that will be after the project implementation (100\% match option). The values to the right of the diagonal indicate the risk values from the fact that the actual value of the expenses after the project will be greater than their values assigned in the project. 
Table 1. Evaluation of pressure pipeline laying options

\begin{tabular}{|c|c|c|c|c|c|c|c|}
\hline № & $\begin{array}{c}\text { Load, } \\
\mathrm{m}^{3} / \mathrm{s}\end{array}$ & $\begin{array}{c}\text { Diameter, } \\
\mathrm{mm}\end{array}$ & $\begin{array}{c}\text { Reduced } \\
\text { costs, } \\
\text { million } \\
\text { rub per } \\
\text { year }\end{array}$ & $\begin{array}{c}\text { Membership } \\
\text { functions } \mu \\
(\mathrm{x})\end{array}$ & $\begin{array}{c}\text { Coeff. of } \\
\text { appreciati } \\
\text { on. } \\
\text { Ku }\end{array}$ & $\begin{array}{c}\text { Reduced } \\
\text { costs } \\
\text { talk into } \\
\text { account } \\
\text { Ku per } \\
\text { year }\end{array}$ & $\begin{array}{c}\text { Option of } \\
\text { preference }\end{array}$ \\
\hline 1 & 0,173 & 315 & 1.05 & 0,01 & 1,99 & 2,10 & 4 \\
\hline 2 & 0,211 & 400 & 1.26 & 0,50 & 1,50 & 1,89 & 2 \\
\hline 3 & 0,249 & 500 & 1.53 & 1,00 & 1,00 & 1,53 & 1 \\
\hline 4 & 0,287 & 600 & 2.52 & 0,50 & 1,50 & 2,30 & 3 \\
\hline 5 & 0,324 & 630 & 2.70 & 0,01 & 1,99 & 5,37 & 5 \\
\hline
\end{tabular}

For example, a flow rate of $0.173 \mathrm{~m}^{3} / \mathrm{s}$ was chosen and a collector $\mathrm{d} 315 \mathrm{~mm}$ was designed, and at the time of completion of construction, the flow rate was $0.211 \mathrm{~m}^{3} / \mathrm{s}$, i.e. $0,027 \mathrm{~m}^{3} / \mathrm{s}$ more. Consequently, pipeline is required overlap on $\mathrm{d} 400 \mathrm{~mm}$, or an extension or parallel installation of a new pipeline, for example, d200 mm with a reduced cost of 0.98 million rubles per year (see table. 2).

Table 2. "Risk matrix"

\begin{tabular}{|c|c|c|c|c|c|c|}
\hline $\begin{array}{c}\text { Loads, } \\
\mathrm{m}^{3} / \mathrm{s}\end{array}$ & 0,173 & 0,211 & 0,249 & 0,287 & 0,324 & $\begin{array}{c}\text { Max, } \\
\text { million rub. per year }\end{array}$ \\
\hline 0,173 & 0 & 0,98 & 1,43 & 1,95 & 2,42 & 2,42 \\
\hline 0,211 & 0,11 & 0 & 0,85 & 1,46 & 2,21 & 2,21 \\
\hline 0,249 & 0,48 & 0,27 & 0 & 1,14 & 2,03 & 2,03 \\
\hline 0,287 & 1,47 & 1,26 & 0,99 & 0 & 1,87 & 1,87 \\
\hline 0,324 & 1,65 & 1,44 & 1,17 & 0,18 & 0 & 1,65 \\
\hline Min & & & & & & 1,65 \\
\hline
\end{tabular}

Table 3. Evaluation of pressure pipeline laying options

\begin{tabular}{|c|c|c|c|c|c|c|c|}
\hline № & $\begin{array}{c}\text { Load, } \\
1 / \mathrm{s}\end{array}$ & $\begin{array}{c}\text { Diameter, } \\
\mathrm{mm}\end{array}$ & $\begin{array}{c}\text { Reduced } \\
\text { costs, } \\
\text { million rub } \\
\text { per year }\end{array}$ & $\begin{array}{c}\text { Membership } \\
\text { functions } \mu \\
(\mathrm{x})\end{array}$ & $\begin{array}{c}\text { Coeff. of } \\
\text { appreciati } \\
\text { on. } \\
\text { Ku }\end{array}$ & $\begin{array}{c}\text { Reduced costs } \\
\text { talk into } \\
\text { account Ku } \\
\text { per year }\end{array}$ & $\begin{array}{c}\text { Option } \\
\text { of } \\
\text { preferen } \\
\text { ce }\end{array}$ \\
\hline 1 & 173 & $2 \mathrm{~d} 500$ & 3,25 & 0,01 & 1,99 & 6,47 & 3 \\
\hline 2 & 211 & $2 \mathrm{~d} 540$ & 3,91 & 0,5 & 1,5 & 5,87 & 2 \\
\hline 3 & 249 & $2 \mathrm{~d} 580$ & 4,61 & 1,0 & 1,0 & 4,61 & 1 \\
\hline 4 & 287 & $2 \mathrm{~d} 630$ & 5,72 & 0,5 & 1,5 & 8,58 & 4 \\
\hline 5 & 324 & $2 \mathrm{~d} 710$ & 6,45 & 0,01 & 1,99 & 12,84 & 5 \\
\hline
\end{tabular}

If the consumption is $0,324 \mathrm{~m}^{3} / \mathrm{s}$, then the risk will already be 2,42 million rubles in year. To the left of the diagonal in the matrix there will be risk values associated with overstatement of parameters and, therefore, with excessive investments. For example, a flow rate of 0,211 $\mathrm{m}^{3} / \mathrm{s}$ was chosen, and after the project implementation, it turned out to be $0,173 \mathrm{~m}^{3} / \mathrm{s}$. For a flow of $0,211 \mathrm{~m}^{3} / \mathrm{s}$, the estimated diameter of the pipeline is $\mathrm{d} 400 \mathrm{~mm}$, and the cost is 1.26 million rubles in year. For a flow rate of $0,173 \mathrm{~m}^{3} / \mathrm{s}$, the calculated diameter is equal to 315 $\mathrm{mm}$, and its costs are 1,05 million rubles in year. Therefore, the risk value is calculated as $1,26-1,05=0,11$ million rubles. The last column of the "risk matrix" presents the maximum risks for each option for making the estimated expense. The last element of this column corresponds to the minimum value of the maximum risks (Savage's criterion [11]). Therefore, from the point of view of minimum risks, the option with a flow rate of $0,324 \mathrm{~m}^{3} / \mathrm{s}$ will be preferable. Although this option is the most expensive at the construction stage (see Table $1)$. 
Example 2. Consider a water supply system consisting of a pumping station and two pressure pipelines with a length of $1 \mathrm{~km}$. The difference of geodetic marks is $55 \mathrm{~m}$. The range of possible loads is $173-324$ l/s. The calculations are presented in tables 3, 4 .

Therefore, from the point of view of minimum risks, the option with a flow rate of 0,174 $\mathrm{m}^{3} / \mathrm{s}$ will be preferable. And this option is the cheapest at the construction stage, although experts put it on position №3 (see Table 3).

Table 4. "Risk matrix"

\begin{tabular}{|c|c|c|c|c|c|c|}
\hline Loads, 1/s & 173 & 211 & 249 & 287 & 324 & $\begin{array}{c}\text { Max, } \\
\text { million rub. per year }\end{array}$ \\
\hline 173 & 0 & 0,62 & 0,76 & 0,81 & 0,97 & 0,97 \\
\hline 211 & 0,66 & 0 & 0,71 & 0,98 & 1,02 & 1,02 \\
\hline 249 & 1,36 & 0,70 & 0 & 0,97 & 1,15 & 1,15 \\
\hline 287 & 2,47 & 1,81 & 1,11 & 0 & 1,28 & 1,28 \\
\hline 324 & 3,20 & 2,54 & 1,84 & 0,73 & 0 & 3,20 \\
\hline Min & & & & & & 0,97 \\
\hline
\end{tabular}

\section{Conclusions}

A new justification method of options for the development, analysis and optimization of the parameters of water supply systems with an assessment of risks from the decisions taken is proposed. This technique is based on the use of a model of fuzzy sets and allows you to take into account the uncertainty of information about the predicted values of specific water consumption in the future.

\section{References}

1. L.A. Shopensky, I.P. Yuriev, Water supply and sanitary engineering, 11, 25 (1985)

2. O.G. Primin, E.I. Pupyrev, Economy of Russia. A look into the future, 142 (ASMOpress., Moscow, 2012)

3. V.F. Kniagin, Yu.A. Perelygin, Expert, 1 (2), 6 (2007)

4. Ukhobotov V.I. Selected chapters of the fuzzy sets theory (Publishing house Chelyab. state University, Chelyabinsk, 2011)

5. B.S. Dobronets, Interval Mathematics: Study Guide ("SFU”, Krasnoyarsk (2007)

6. NTsS 81-02-14-2012, Water supply and sewage networks (Moscow, 2012)

7. S.V. Khramenkov, V.A. Orlov, V.A. Kharkin, Optimization of restoration of drainage networks (Stroiizdat, Moscow, 2002)

8. V.P. Salomeev, Reconstruction of engineering systems and water disposal facilities (Publishing House of the Association of Construction Universities, Moscow, 2009)

9. SP 32.13330.2012 Sewerage. External systems and facilities

10. P.I. Pakhomov, V.A. Nemtikov, Technology support decision-making management of engineering communications (Mashinostroenie, Moscow, 2009)

11. Z. Mushik, P. Muller Methods of making technical decisions (Mir, Moscow, 1990)

12. O.G. Primin, V.S. Bortkevich, V.I. Mirkus, and other, Water supply and sanitary equipment, 7, 28 (2014)

13. E.S. Melekhov, V.R. Chupin, R.V. Chupin, Certificate of state registration of the computer program №2016615463 TRACE-VR dated May 25, (2016) 